\title{
National Metrical Types in Nineteenth Century Art Song
}

\author{
LEIGH VANHANDEL \\ Michigan State University
}

\begin{abstract}
William Rothstein's article "National metrical types in music of the eighteenth and early nineteenth centuries" (2008) proposes a distinction between the metrical habits of $18^{\text {th }}$ and early $19^{\text {th }}$ century German music and those of Italian and French music of that period. Based on theoretical treatises and compositional practice, he outlines these national metrical types and discusses the characteristics of each type. This paper presents the results of a study designed to determine whether, and to what degree, Rothstein's characterizations of national metrical types are present in $19^{\text {th }}$ century French and German art song. Studying metrical habits in this genre may provide a lens into changing metrical conceptions of $19^{\text {th }}$ century theorists and composers, as well as to the metrical habits and compositional style of individual $19^{\text {th }}$ century French and German art song composers.
\end{abstract}

Submitted 2009 October 8; accepted 2009 November 19.

KEYWORDS: meter, $19^{\text {th }}$-century art song, barring, phrasing

\section{INTRODUCTION AND BACKGROUND}

WILLIAM Rothstein's article "National metrical types in music of the eighteenth and early nineteenth centuries" (2008) outlines characteristics and 'metrical habits' in German music of that time period that are different from those in Italian and French music. He summarizes:

I had long been aware that the structure and function of the musical bar changed between the early eighteenth and the early nineteenth centuries, but studying nineteenth-century opera has convinced me that this change included a strongly national component: metrical habits that are rare in German music after 1820 survive undisturbed in music by Italian and French composers. By 'metrical habits' I mean, above all, the habits of composers in placing their barlines. Broadly speaking, Italian and French composers were much more likely in the nineteenth century to place cadences on the first beat of a bar, whereas German composers often placed them later. Conversely, phrases in German music were less likely to begin in mid-bar, beginning instead on the downbeat or with a short anacrusis, one-third of a bar or less in length (Rothstein, 2008, pp. 112-113).

Rothstein's article discusses historical conceptions of barring practices and metrical theories from late $18^{\text {th }}$ and early $19^{\text {th }}$ century composers and theorists, develops his 'national metrical types' based on theorists' writings and composer practice in the time period, and concludes with a survey of Mozart's Italian operas, serenatas, and concert arias illustrating his principles.

This paper presents the results of a study designed to determine whether and to what degree Rothstein's characterizations of national metrical types, including phrase beginnings and endings and treatment of compound meter, are present in a slightly later genre, that of $19^{\text {th }}$ century French and German art song. Studying metrical habits in composers of the $19^{\text {th }}$ century may provide a lens into the changing metrical conceptions of $19^{\text {th }}$ century theorists and composers, as well as to the metrical habits and compositional style of individual $19^{\text {th }}$ century French and German art song composers. 


\section{METHODS}

The current study uses a large database created using David Huron's Humdrum Toolkit, an open source software package designed to assist with music research. The database consists of complete melodic, rhythmic, phrasing, and text/lyric information from over a thousand $19^{\text {th }}$ century French and German solo vocal art songs by 29 composers, as shown in Table 1.

These composers were chosen as representatives of $19^{\text {th }}$ century French and German art song traditions based upon reputation within the genre, gender, availability of sufficient repertoire for study, and the provision of data points distributed across the 19th century. In cases where composers had authored a large number of songs, a representative sample was selected from different periods of their life. The primary selection criteria were only that the songs be secular solo vocal works with piano accompaniment, and be composed before 1900 by French and German composers. To avoid translation issues, both the composer and poet had to be native speakers of the language, with the text originally written in that language. The only other exclusions were stylistic pieces such as Chinoise and songs that had been excerpted from operas.

$\begin{array}{llll}\text { French } & \# & \text { German } & \# \\ \text { Bizet } & 24 & \text { Beethoven } & 18 \\ \text { Chabrier } & 9 & \text { Brahms } & 52 \\ \text { Chaminade } & 19 & \text { Franz } & 61 \\ \text { Chausson } & 30 & \text { Hensel } & 47 \\ \text { David } & 33 & \text { Lang } & 26 \\ \text { Debussy } & 33 & \text { Loewe } & 9 \\ \text { Duparc } & 14 & \text { Mahler } & 19 \\ \text { Fauré } & 64 & \text { Mendelssohn } & 57 \\ \text { Gounod } & 51 & \text { Schubert } & 121 \\ \text { Holmés } & 16 & \text { C. Schumann } & 7 \\ \text { Lalo } & 15 & \text { R. Schumann } & 123 \\ \text { Massé } & 20 & \text { Strauss } & 33 \\ \text { Massenet } & 39 & \text { Wolf } & 82 \\ \text { Reber } & 30 & & \\ \text { Reyer } & 8 & & \\ \text { Saint-Saëns } & 7 & & \\ & & & \end{array}$

Table 1. Composers and number of songs represented in the database.

Each song in the database consists of an encoding of the melodic, rhythmic, phrasing, tempo, and lyric information for the vocal line only. Phrasing was determined by highly trained musicians and encoded into the database with the melodic and rhythmic information. Phrasing decisions were based upon a set of musical factors that contribute to phrasing in vocal songs, including rests, punctuation, harmonic progressions and cadences, and phrase markings provided by the composer. In cases where an encoder had questions regarding phrasing, two other analysts were consulted and the prevailing interpretation was used. Files were checked at random by other analysts for accuracy and for agreement with phrasing decisions; in cases where an analyst had a different interpretation for a randomly checked file, a third analyst was consulted and the prevailing interpretation was used.

\section{DISCUSSION}

Rothstein's article describes what he refers to as "national metrical types." He begins his explanation of what constitutes a national metrical type by discussing $18^{\text {th }}$ and $19^{\text {th }}$ century barring and phrasing practices, outlining what he refers to as the German, Italian, and neutral styles of barring and phrasing. He then extends these barring and 
phrasing practices to the study of compound meter during this time period, using the practices to describe what he calls the characteristics of German compound meter and of Franco-Italian compound meter.

Rothstein's article contains testable hypotheses regarding nationalistic differences in phrase beginning and ending locations, and metrical characteristics. The discussion that follows below alternates between summarizing Rothstein's characterizations and presenting the results of studies run using the Humdrum database of $19^{\text {th }}$ century art songs. The goal of these studies was to determine whether the characteristics described by Rothstein were present in the music of $19^{\text {th }}$ century French and German composers. While Rothstein's article included a survey of a large amount of $18^{\text {th }}$ and early $19^{\text {th }}$ century repertoire, it was not a database-driven study; all references to a 'database' refer to the Humdrum database of $19^{\text {th }}$ century French and German art song described above.

\section{Barring Practices}

Rothstein highlights differences in $18^{\text {th }}$ and $19^{\text {th }}$ century barring practices based on composer nationality or, in the case of opera, language. His discussion of barring practices focuses on composers and theorists whose barring (or rebarring) of pieces indicated a preference for phrase beginnings and cadence locations. Rothstein describes three types of barring practices: German barring, in which phrase beginnings are generally placed on downbeats or consist of a very short anacrusis, and phrase endings typically occur mid-measure; Italian barring, in which "cadences are always placed just to the right of the barline, and in which phrases begin at least half a bar to the left of the barline"; and neutral barring, which describes pieces notated in a simple meter with "cadences placed on downbeats and $\ldots$ without long upbeats". Rothstein points out that much French music of the late $18^{\text {th }}$ and early $19^{\text {th }}$ centuries follows the Italian barring style, and also claims that neutral barring is "extremely common in vocal music of the late eighteenth century" (Rothstein, 2008, pp. 115-117). ${ }^{[1]}$

This study examines barring practice in $19^{\text {th }}$ century French and German art song in four metrical categories: simple triple, compound duple, simple duple, and simple quadruple. These four metrical categories encompass a variety of notated meter signatures: simple triple may be expressed as $3 / 4,3 / 8$, etc.; compound duple may include 6/8,6/16, etc.; examples of simple duple include $2 / 4,4 / 8$, etc.; and simple quadruple may be notated as 4/4. As Table 2 illustrates, phrases in these four metrical categories make up over $90 \%$ of the total number of phrases in the current study's database for both French and German composers (91.68\% for French, 93.88\% for German).

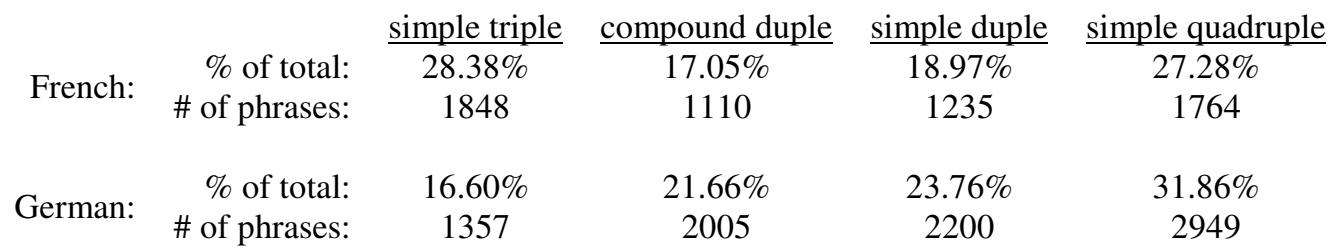

Table 2. Percentage of total and total number of phrases of each metrical category.

\section{DETERMINING PHRASE BEGINNINGS AND ENDINGS}

Determining the metrical location of a phrase beginning is straightforward; the onset of the first note of a phrase represents the metrical location of the beginning of the phrase. However, the metrical location of the phrase ending or cadence is more difficult to determine and requires some discussion.

In general, the onset of the final note of the phrase is considered the location of the cadence, except when the final notated pitch is part of a longer tied note, in which case the metrical location of the first note of the tied note is considered the arrival of the cadence. ${ }^{[2]}$ This is different than Rothstein's method of determining cadence location; his approach was to consider the cadence arrival as the moment at which its bass note appeared. As the database for the current study only contains melodic information, it is not possible to use a harmonically-based method for determining cadential arrival.

Two issues of text-setting need to be addressed with respect to identifying cadential locations. First, certain French dialects contain a mute -e, which may or may not be set to its own pitch. In situations where it does receive its own pitch, the cadence location may have appeared at the beginning of the word, and counting the mute -e as the end of the phrase would make the cadence appear to be later in the measure than it actually is. A study of the 6,474 
French phrases in the database indicates that there are a total of 279 phrases in which the mute -e occurs in a phrasefinal location. It is likely that in at least some of these cases, the harmonic cadence would align with the arrival of the mute $-\mathrm{e}$. However, the overall small number of phrase-final mute -e's will not have a significant effect on the overall calculation of phrase endings.

The second text-setting issue occurs when a single syllable is set to more than one pitch, the last of which is the phrase-final pitch. Again, the cadential location may be ambiguous in this case. A survey of the database indicates that this happens in 288 of the 6,474 French phrases and in 519 of the 9,113 German phrases; again, this small number of phrases is unlikely to have a significant effect on the overall calculation of phrase endings. In addition, it is quite likely that in a number of these phrases, the final pitch is the melodic cadence; for example, this would be the case if the final syllable was set with a suspension.

\section{PHRASE BEGINNINGS}

Based on Rothstein's description of barring practices, we expect French phrases to adhere to the Italian barring style; for phrase beginnings, this consists of a relatively long anacrusis, meaning that French phrases should begin earlier in the measure. German phrases, with a shorter anacrusis, should begin later in the measure.

To test these expectations using the current study's database, a program written within the Humdrum environment identified the metrical location of phrase beginnings and cadences. Another program converted that metrical location into a number. For example, in simple triple meters, the downbeat is considered " 1 ", the second beat " 2 ", and the third beat " 3 ". If a phrase begins on the eighth note between beats 1 and 2 , the phrase beginning is recorded as 1.5. This system is also used for simple duple and simple quadruple meters. For compound duple meters, the downbeat is considered as beat " 1 " and the secondary stress of the measure (for example, the fourth eighth note in 6/8) is considered beat " 2 ". If a phrase begins on the third eighth note of a 6/8 measure, for example, the starting location is recorded as 1.66. These numerical representations of metrical starting location are then averaged to determine the average metric location for phrase beginnings.

Table 3 illustrates the average metric location of the beginnings of phrases for each of the four metrical categories in the study, calculated using the method above. Smaller average metric locations indicate that phrases begin earlier in the measure.

\begin{tabular}{|c|c|c|c|c|}
\hline & simple triple & compound duple & simple duple & simple \\
\hline French & 2.17 & 1.74 & 1.72 & 2.73 \\
\hline German & 2.35 & 2.16 & 1.94 & 2.98 \\
\hline
\end{tabular}

Table 3. Average metric location for phrase beginnings in the $19^{\text {th }}$ century French and German songs.

In each metrical category, the average metrical location for phrase beginnings is earlier in the measure for the $19^{\text {th }}$ century French composers than for the German composers. This difference is statistically significant for simple triple, compound duple, and simple duple ( $t=1.87, p=.03 ; t=5.17, p<.001 ; t=1.74, p=.04$, respectively).

However, Rothstein's description of German barring characteristics indicates that German phrases may either have a very short anacrusis, thus beginning late in the measure, or that German phrases may begin directly on the downbeat of a measure. If German composers do frequently begin phrases on beat 1 , the average metrical placement for the German phrase beginnings calculated in Table 3 will appear to be closer to the beginning of the measure than it would otherwise. To determine if German composers do tend to begin phrases directly on the downbeat, we can calculate the percentage of phrases by both French and German composers that begin directly on the downbeat of a measure; this data is presented in Table 4 .

\begin{tabular}{|c|c|c|c|c|}
\hline & simple triple & compound duple & simple duple & simple quadruple \\
\hline Fren & $32.05 \%$ & $29.12 \%$ & $29.44 \%$ & $23.81 \%$ \\
\hline Gerı & $27.72 \%$ & $19.13 \%$ & $30.17 \%$ & $22.13 \%$ \\
\hline
\end{tabular}

Table 4. Percentage of phrases that begin on beat 1 in both French and German songs. 
In this repertory, German composers do not appear to begin phrases on a metrical downbeat more frequently than the French composers, as Rothstein would predict; in fact, the French composers begin phrases on the downbeat more frequently than German composers in three of the four metrical categories, and the percentage difference is significant in compound duple $(t=-1.67, p=.05)$.

If we calculate the average metrical location for phrase beginnings without including phrases that begin immediately on the downbeat, it will represent the average metrical location for non-downbeat phrase beginnings. Table 5 presents the average metrical location for phrase beginnings when phrases that begin on the downbeat are excluded.

\begin{tabular}{|c|c|c|c|c|}
\hline & simple triple & compound duple & simple duple & simple quadruple \\
\hline French & 2.72 & 2.04 & 2.02 & 3.27 \\
\hline German & 2.87 & 2.44 & 2.35 & 3.55 \\
\hline
\end{tabular}

Table 5. Average metrical location for phrase beginnings, excluding phrases beginning on downbeats.

The average metrical location for phrases that do not begin on a downbeat is still later in the measure for German composers than for French for all metrical types. This result is significant for compound duple and simple duple $(t=$ $4.55, p<.001 ; t=3.58, p<.001$, respectively).

\section{PHRASE ENDINGS}

The other characteristic that distinguishes between Rothstein's barring types is the location of the cadence, or phrase ending. According to Rothstein, Italian barring should have the majority of its cadences on the downbeat of the measure; Rothstein asserts that this characteristic is linked to "the idea that there can be no stronger beat within the notated bar than that on which the cadence falls. "In the nineteenth century, this principle was followed more often by French and Italian composers than by German ones" (Rothstein, 2008, p. 121). Neutral barring also follows this principle; however, the "identifying feature of German barring is the regular placement of cadences on relatively weak beats" (Rothstein, 2008, p. 116).

Thus, according to Rothstein, $18^{\text {th }}$ century French and Italian composers ended phrases on beat 1 more frequently than German composers in that era, who were more likely to cadence on a secondary stressed beat in the measure. In simple and compound duple, the secondary stress would occur on beat 2; for simple quadruple, beat 3 ; and in simple triple, there is no consistent secondary stress location.

Based on Rothstein's characteristics, the average metrical cadence location for the $19^{\text {th }}$ century French composers in the database should be closer to the downbeat than the average metrical location for the German composers. Table 6 shows the average metrical location for cadences for all phrases in the French and German songs in the study's database.

\begin{tabular}{|c|c|c|c|c|}
\hline & simple triple & compound duple & simple duple & simple quadruple \\
\hline French & 1.69 & 1.45 & 1.42 & 2.01 \\
\hline German & 1.66 & 1.56 & 1.51 & 2.30 \\
\hline
\end{tabular}

Table 6. Average metrical location for cadences for all phrases.

With the exception of simple triple meters, which do not have a consistent secondary stress location for midmeasure cadences, the $19^{\text {th }}$ century French composers do appear to end phrases earlier in a measure than the German composers. However, none of these differences are statistically significant due to variations in individual composers, some of which will be discussed later.

As mentioned, Rothstein would expect French composers to cadence on the downbeat more frequently than German composers. To determine if this is the case, we can calculate the percentage of phrases in each metrical category that end on the downbeat of the measure. Table 7 illustrates the percentages of French and German phrases that end on the downbeat. 


\begin{tabular}{|c|c|c|c|c|}
\hline & simple triple & compound duple & simple duple & simple quadruple \\
\hline French & $51.01 \%$ & $54.84 \%$ & $55.40 \%$ & $44.74 \%$ \\
\hline German & $53.01 \%$ & $43.15 \%$ & $45.73 \%$ & $35.55 \%$ \\
\hline
\end{tabular}

Table 7. Percentage of phrases that cadence on the downbeat in both French and German songs.

With the exception of phrases in simple triple meters, more $19^{\text {th }}$ century French phrases do cadence directly on the downbeat than German phrases. Despite the apparent large difference in some of the percentages, none of the differences are statistically significant, again due to variations across individual composers. The percent difference for compound duple is the closest to statistical significance at $t=-1.33, p=.09$.

As with phrase beginnings, if we remove phrases that contain downbeat cadences we can determine where phrases cadence when they do not occur on the downbeat. Table 8 illustrates the average metrical location for phrases that do not cadence on the downbeat.

\begin{tabular}{|c|c|c|c|c|}
\hline & simple triple & compound duple & simple duple & simple quadruple \\
\hline French & 2.36 & 2.01 & 1.93 & 2.86 \\
\hline German & 2.35 & 1.95 & 1.94 & 2.88 \\
\hline
\end{tabular}

Table 8. Average metrical location for phrase cadences that do not occur on the downbeat.

The results are very similar across languages: the average non-downbeat cadence location is between beats 2 and 3 for simple triple meters, close to the secondarily stressed beat 2 for compound duple and simple duple meters, and close to the secondarily stressed beat 3 for simple quadruple meters. None of the average non-downbeat cadence locations are significantly different across languages, although compound duple is close to significance at $t=-1.53$, $p=.06$. For compound duple, the average metrical location for the cadence for German composers is actually slightly earlier in the measure than is the average metrical location for cadences by French composers.

\section{BARRING TYPES SUMMARY}

In his description of phrase beginning locations, Rothstein asserted that German phrase beginnings either occur with a short anacrusis, thus beginning late in the measure, or begin immediately on the downbeat. By contrast, French composers, following the Italian barring style, would begin phrases with a long anacrusis, thus having the phrase beginning appear earlier in the measure. Regarding phrase ending locations, Rothstein claimed that French composers, again following the Italian barring style, would tend to notate their phrase endings so that the cadence fell on the downbeat, whereas the German composers would frequently end on a relatively weak beat. These hypotheses regarding phrase beginnings and endings were tested using the Humdrum database of $19^{\text {th }}$ century French and German art song to determine to what degree these characteristics were present in that repertoire.

In general, the $19^{\text {th }}$ century German composers do appear to begin phrases later in the measure than the $19^{\text {th }}$ century French composers. However, the German composers do not begin their phrases on the downbeat more frequently than do the French composers; the rate of occurrence is approximately the same except in compound duple meters, where French composers begin their phrases on the downbeat significantly more frequently than German composers.

For phrase ending location, French composers do appear to cadence on the downbeat more frequently than do the German composers, although none of the results reach the level of statistical significance.

Based on these results, it appears as though the $19^{\text {th }}$ century French art song composers were somewhere in between what Rothstein refers to as the Italian barring practice and the neutral barring practice, which he described as consisting of frequent cadences on the downbeat and phrase beginnings that either occurred on the downbeat or with relatively short upbeats. The $19^{\text {th }}$ century French composers began phrases on the downbeat approximately as often as German composers, or even significantly more frequently, in the case of compound duple meters (Table 4). When looking at where French composers began phrases that didn't begin on the downbeat (Table 5), the starting metrical location is earlier than German, but only significantly so for compound duple and simple duple. This 
implies that while the French composers do tend to begin their phrases earlier in the measure, it may not be a feature that necessarily distinguishes their style from German compositional style in all metrical categories in this genre.

\section{Compound Meters}

Rothstein next focuses his discussion on the varying and changing interpretations of specific meter signatures that were considered compound meters: $4 / 4,6 / 8$, and $12 / 8$. Many $18^{\text {th }}$-century theorists considered $4 / 4$ to be a compound meter consisting of two equally weighted bars of 2/4; others (including Kirnberger, Vogler, and Türk) considered the compound $4 / 4$ as containing two $2 / 4$ measures with the second subordinate to the first. Rothstein then extends the characteristics that determined barring practices, outlined above, to these compound meters, defining three types of nationalistic compound meter types. He describes French compound meter as being a compound measure where "caesuras and cadences fall exclusively on the first half of the bar; incises and phrases begin with long upbeats." German compound meter is defined as when "caesuras and cadences fall mostly, if not exclusively, in the second half of the bar. Upbeats, where present, are rarely more than one beat in length." The third type of compound meter is the Italian compound meter, in which "[c]aesuras and cadences fall in either half of the compound bar; there is little or no perceived difference between the halves" (Rothstein, 2008, pp. 134-135). (These three compound metrical types correspond roughly to the Italian, German, and neutral barring style, respectively.)

Rothstein dismisses the Italian compound meter, corresponding to the neutral barring practice, as not being a proper compound meter, as it is not possible to tell the difference between the first half of the bar and the second:

$\ldots$ an experienced listener should have no difficulty telling which half of the bar she is hearing at any moment. Wherever this is true, the compound meter is either German or French. Where there is frequent doubt on this point, the compound meter is Italian, or (much the same thing) the meter is not perceived as compound (Rothstein, 2008, p. 136).

Rothstein notes that by 1820, the concepts of French compound meter and Italian barring practices essentially merged, leaving a compound metrical type he calls Franco-Italian compound meter, which he contrasts with German compound meter. He also asserts that "[b]y 1820, German meter was well established as a compositional framework, not only in Germany but further afield, while Franco-Italian meter continued to be used, at least in France and Italy" (Rothstein, 2008, p. 146).

The previous section discussed the overall metrical tendencies for phrase beginnings and cadences in the compound duple and simple quadruple phrases in the database. As mentioned previously in the discussion of phrase endings in metrical categories, there is a great deal of variation between individual composers within each language, which makes it difficult to identify any cross-language trends. It is worthwhile to look at how the characteristics are manifested in individual composers' treatment of compound meters.

The following discussion will focus on the metrical categories of compound duple (representing 6/8) and simple quadruple (representing the "compound" $4 / 4$ measure). Compound quadruple (12/8) is not included in the current study because it occurs relatively infrequently in the database; only nine of the sixteen French composers represented in the study used it, for a total of 206 phrases, or a mere $3.16 \%$ of the total number of French phrases, and only seven of the thirteen German composers used compound quadruple meter, for a total of 204 phrases, or $2.20 \%$ of the total number of German phrases.

Table 9 provides the average metrical location for phrase beginnings, both with and without phrases that begin on the downbeat, for each $19^{\text {th }}$ century French and German composer in the database; it also lists the percentage of time that each composer began phrases on the downbeat or secondarily stressed beat of that meter. 


\begin{tabular}{|c|c|c|c|c|c|c|c|c|}
\hline & \multicolumn{4}{|c|}{ compound duple } & \multicolumn{4}{|c|}{ simple quadruple } \\
\hline & $\begin{array}{c}\text { avg. } \\
\text { with } \\
\text { downbeats }\end{array}$ & $\begin{array}{c}\text { avg. } \\
\text { without } \\
\text { downbeats }\end{array}$ & $\begin{array}{c}\% \\
\text { beginning } \\
\text { on beat } 1\end{array}$ & $\begin{array}{c}\% \\
\text { beginning } \\
\text { on beat } 2\end{array}$ & $\begin{array}{c}\text { avg. } \\
\text { with } \\
\text { downbeats }\end{array}$ & $\begin{array}{c}\text { avg. } \\
\text { without } \\
\text { downbeats }\end{array}$ & $\begin{array}{c}\% \\
\text { beginning } \\
\text { on beat } 1\end{array}$ & $\begin{array}{c}\% \\
\text { beginning } \\
\text { on beat } 3\end{array}$ \\
\hline $\begin{array}{l}\text { French } \\
\text { overall }\end{array}$ & 1.74 & 2.04 & $29.12 \%$ & $22.76 \%$ & 2.73 & 3.27 & $23.81 \%$ & $11.74 \%$ \\
\hline Bizet & 1.66 & 1.95 & $30.43 \%$ & $29.35 \%$ & 2.84 & 3.38 & $22.66 \%$ & $9.38 \%$ \\
\hline Chabrier & 1.96 & 2.17 & $18.52 \%$ & $18.52 \%$ & 3.07 & 3.24 & $7.32 \%$ & $2.44 \%$ \\
\hline Chaminade & 1.40 & 1.80 & $50.00 \%$ & $27.27 \%$ & 2.24 & 3.50 & $50.43 \%$ & $1.71 \%$ \\
\hline Chausson & 1.75 & 1.99 & $24.49 \%$ & $20.41 \%$ & 2.37 & 2.70 & $19.16 \%$ & $10.78 \%$ \\
\hline David & 2.02 & 2.29 & $20.97 \%$ & $27.42 \%$ & 2.85 & 3.24 & $17.24 \%$ & $29.89 \%$ \\
\hline Debussy & 1.71 & 1.81 & $12.33 \%$ & $41.10 \%$ & 2.61 & 2.76 & $8.90 \%$ & $9.95 \%$ \\
\hline Duparc & 1.72 & 2.05 & $31.58 \%$ & $23.68 \%$ & 3.23 & 3.46 & $9.28 \%$ & $7.22 \%$ \\
\hline Fauré & 1.64 & 1.98 & $34.83 \%$ & $15.73 \%$ & 2.68 & 3.45 & $31.45 \%$ & $6.45 \%$ \\
\hline Gounod & 1.66 & 1.93 & $29.36 \%$ & $16.97 \%$ & 2.80 & 3.48 & $27.17 \%$ & $19.33 \%$ \\
\hline Holmés & 1.74 & 2.67 & $55.88 \%$ & $0.00 \%$ & 2.69 & 4.34 & $49.44 \%$ & $0.00 \%$ \\
\hline Lalo & 1.96 & 2.02 & $5.80 \%$ & $31.88 \%$ & 4.04 & 4.04 & $0.00 \%$ & $0.00 \%$ \\
\hline Massé & 1.60 & 2.07 & $44.19 \%$ & $23.26 \%$ & 3.09 & 3.48 & $15.52 \%$ & $10.34 \%$ \\
\hline Massenet & 1.90 & 2.12 & $19.84 \%$ & $26.19 \%$ & 2.65 & 3.00 & $17.54 \%$ & $2.63 \%$ \\
\hline Reber & 1.78 & 2.40 & $43.82 \%$ & $8.99 \%$ & 2.97 & 3.36 & $16.67 \%$ & $36.36 \%$ \\
\hline Reyer & 2.19 & 2.19 & $0.00 \%$ & $55.56 \%$ & 3.21 & 4.10 & $28.57 \%$ & $0.00 \%$ \\
\hline \multirow[t]{3}{*}{ Saint-Saëns } & 1.58 & 1.90 & $36.36 \%$ & $45.45 \%$ & 2.87 & 3.32 & $19.30 \%$ & $21.05 \%$ \\
\hline & \multicolumn{4}{|c|}{ compound duple } & \multicolumn{4}{|c|}{ simple quadruple } \\
\hline & $\begin{array}{c}\text { avg. } \\
\text { with } \\
\text { downbeats }\end{array}$ & $\begin{array}{c}\text { avg. } \\
\text { without } \\
\text { downbeats }\end{array}$ & $\begin{array}{c}\% \\
\text { beginning } \\
\text { on beat } 1\end{array}$ & $\begin{array}{c}\% \\
\text { beginning } \\
\text { on beat } 2\end{array}$ & $\begin{array}{c}\text { avg. } \\
\text { with } \\
\text { downbeats }\end{array}$ & $\begin{array}{c}\text { avg. } \\
\text { without } \\
\text { downbeats }\end{array}$ & $\begin{array}{c}\% \\
\text { beginning } \\
\text { on beat } 1\end{array}$ & $\begin{array}{c}\% \\
\text { beginning } \\
\text { on beat } 3\end{array}$ \\
\hline $\begin{array}{r}\text { German } \\
\text { overall }\end{array}$ & 2.16 & 2.44 & $19.13 \%$ & $10.08 \%$ & 2.98 & 3.55 & $22.13 \%$ & $7.22 \%$ \\
\hline Beethoven & 2.19 & 2.22 & $1.89 \%$ & $58.49 \%$ & 2.64 & 4.00 & $45.45 \%$ & $0.00 \%$ \\
\hline Brahms & 2.23 & 2.43 & $13.95 \%$ & $6.40 \%$ & 3.13 & 3.78 & $23.29 \%$ & $4.57 \%$ \\
\hline Franz & 2.32 & 2.59 & $16.67 \%$ & $5.21 \%$ & 3.01 & 4.03 & $33.70 \%$ & $2.17 \%$ \\
\hline Hensel & 2.16 & 2.43 & $18.81 \%$ & $6.93 \%$ & 2.72 & 3.36 & $26.97 \%$ & $22.10 \%$ \\
\hline Lang & 1.86 & 2.67 & $48.28 \%$ & $0.00 \%$ & 2.69 & 3.52 & $33.01 \%$ & $12.62 \%$ \\
\hline Loewe & 2.54 & 2.59 & $2.94 \%$ & $2.94 \%$ & 4.02 & 4.07 & $1.49 \%$ & $0.00 \%$ \\
\hline Mahler & 2.08 & 2.58 & $31.25 \%$ & $0.00 \%$ & 3.66 & 3.76 & $3.45 \%$ & $1.15 \%$ \\
\hline Mendelssohn & 1.93 & 2.42 & $34.70 \%$ & $15.53 \%$ & 2.95 & 3.27 & $14.04 \%$ & $14.61 \%$ \\
\hline Schubert & 2.31 & 2.51 & $13.78 \%$ & $6.30 \%$ & 3.39 & 3.88 & $16.98 \%$ & $3.31 \%$ \\
\hline C. Schumann & 2.10 & 2.28 & $14.29 \%$ & $14.29 \%$ & 3.39 & 3.39 & $0.00 \%$ & $0.00 \%$ \\
\hline R. Schumann & 2.13 & 2.47 & $23.26 \%$ & $9.72 \%$ & 3.14 & 3.74 & $21.58 \%$ & $5.92 \%$ \\
\hline Strauss & 1.93 & 2.09 & $15.15 \%$ & $15.15 \%$ & 2.76 & 3.07 & $14.86 \%$ & $1.71 \%$ \\
\hline Wolf & 2.00 & 2.26 & $21.13 \%$ & $13.40 \%$ & 2.34 & 2.96 & $31.41 \%$ & $7.51 \%$ \\
\hline
\end{tabular}

Table 9. Average metrical location of phrase beginnings, with and without downbeats, and percentage of phrases beginning on downbeat or secondarily stressed beat. 
As discussed previously, the average overall phrase beginning location in compound duple was significantly different between the $19^{\text {th }}$ century French and German composers. Based on the characteristics of Rothstein's Franco-Italian and German compound meters, we expect the French composers to have average phrase beginnings that occur before the secondarily stressed beat in compound duple meters, and German composers to have average phrase beginnings that occur after the secondarily stressed beat. When looking at the averages for the individual composers, we can see the variability in individual compositional style. For example, we see that seven of the sixteen French composers represented in the database have average phrase beginning locations that fit the Franco-Italian compound meter profile, whereas all of the German composers fit the German compound meter characteristics.

The average overall phrase beginning location in simple quadruple was not significantly different across the $19^{\text {th }}$ century French and German composers, and the data for the individual composers illustrates that while the average phrase beginning location for German composers is indeed later in the measure than the average for French composers, the variability across composers within each language means that this is not a characteristic that can be used to distinguish French and German composers from one another.

Looking at how frequently individual composers began phrases on stressed or secondarily stressed beats can also provide an insight into individual compositional style. Augusta Holmés provides a striking example of this: while she began phrases on the downbeat of both compound duple and simple quadruple approximately half of the time $(55.88 \%$ and $49.44 \%$, respectively), she did not begin phrases on the secondarily stressed beat of the measure. Combining this data with her remarkably late average phrase beginning locations of 2.67 for compound duple, and 4.34 for simple quadruple, we can see that she tended to begin phrases on the downbeat, and when she didn't begin on downbeats, her phrases had extremely short anacruses; in other words, Holmés' compositional style in these two metrical categories is much more similar to that of the German composers in the database, and to the German barring style described by Rothstein, than the other French composers.

In addition, we can also see when a composer treats phrase beginnings in these two metrical categories differently. For example, in compound duple meters, Ernst Reyer never began phrases on the downbeat of the measure, but frequently began phrases on the secondarily stressed beat $(55.56 \%)$; in simple quadruple meters, he reversed this pattern, beginning phrases on the downbeat $28.57 \%$ of the time, but never beginning phrases on the secondarily stressed beat. In addition, his average phrase beginning location is comparatively much later in simple quadruple meters than it is in compound duple meters. Similarly, Beethoven began phrases on the secondarily stressed beat in compound duple meters far more often than he began them on the downbeat (58.49\% compared to $1.89 \%$ ), but reversed this in simple quadruple, beginning on the downbeat $45.45 \%$ of the time and never beginning on the secondarily stressed beat 3 .

Table 10 provides the average metrical location for phrase endings, both with and without phrases that end on the downbeat, for each individual French and German composer; it also lists the percentage of time that each composer ended phrases on the downbeat or secondarily stressed beat of that meter. Based on the characteristics of Rothstein's Franco-Italian and German compound meters, we expect French composers to end on the downbeat more frequently than German composers, and we expect German composers to end phrases on the secondarily stressed beat more frequently than French composers. This is the case overall, although as mentioned, none of the differences in cross-language overall averages are statistically significant. French composers end phrases on the downbeat more frequently than do German composers (compound duple: $54.84 \%$ vs. 43.15\%; simple quadruple: $44.74 \%$ vs. $35.55 \%$ ), and are overall less likely to end on the secondarily stressed beat (compound duple: $29.39 \%$ vs. $39.51 \%$; simple quadruple: $28.48 \%$ vs. $33.77 \%$ ). The overall percentages also illustrate that for both metrical categories, while the French composers are more likely to end phrases on the downbeat, the German composers end on either the downbeat or the secondarily stressed beat approximately the same percentage of the time; this supports Rothstein's assertion that this metrical habit persisted in $19^{\text {th }}$ century German compositional style. 


\begin{tabular}{|c|c|c|c|c|c|c|c|c|}
\hline & \multicolumn{4}{|c|}{ compound duple } & \multicolumn{4}{|c|}{ simple quadruple } \\
\hline & $\begin{array}{c}\text { avg. } \\
\text { with } \\
\text { downbeats }\end{array}$ & $\begin{array}{c}\text { avg. } \\
\text { without } \\
\text { downbeats }\end{array}$ & $\begin{array}{c}\% \\
\text { ending } \\
\text { on beat } 1\end{array}$ & $\begin{array}{c}\% \\
\text { ending } \\
\text { on beat } 2\end{array}$ & $\begin{array}{c}\text { avg. } \\
\text { with } \\
\text { downbeats }\end{array}$ & $\begin{array}{c}\text { avg. } \\
\text { without } \\
\text { downbeats }\end{array}$ & $\begin{array}{c}\% \\
\text { ending } \\
\text { on beat } 1\end{array}$ & $\begin{array}{c}\% \\
\text { ending } \\
\text { on beat } 3\end{array}$ \\
\hline $\begin{array}{l}\text { French } \\
\text { overall }\end{array}$ & 1.45 & 2.01 & $54.84 \%$ & $29.39 \%$ & 2.01 & 2.86 & $44.74 \%$ & $28.48 \%$ \\
\hline Bizet & 1.50 & 1.93 & $46.24 \%$ & $31.18 \%$ & 1.99 & 2.61 & $38.28 \%$ & $31.25 \%$ \\
\hline Chabrier & 1.53 & 2.24 & $57.69 \%$ & $26.92 \%$ & 2.37 & 2.75 & $21.95 \%$ & $31.71 \%$ \\
\hline Chaminade & 1.51 & 1.97 & $47.62 \%$ & $42.86 \%$ & 2.16 & 2.81 & $35.77 \%$ & $30.89 \%$ \\
\hline Chausson & 1.49 & 2.05 & $53.06 \%$ & $22.45 \%$ & 2.12 & 3.13 & $47.53 \%$ & $25.31 \%$ \\
\hline David & 1.18 & 1.92 & $80.65 \%$ & $14.52 \%$ & 1.63 & 2.50 & $57.95 \%$ & $18.18 \%$ \\
\hline Debussy & 1.63 & 2.11 & $43.06 \%$ & $36.11 \%$ & 2.01 & 2.85 & $45.26 \%$ & $25.79 \%$ \\
\hline Duparc & 1.47 & 2.11 & $57.89 \%$ & $26.32 \%$ & 1.78 & 2.78 & $56.12 \%$ & $22.45 \%$ \\
\hline Fauré & 1.59 & 2.01 & $41.57 \%$ & $31.46 \%$ & 2.09 & 3.03 & $46.12 \%$ & $31.02 \%$ \\
\hline Gounod & 1.49 & 2.06 & $53.49 \%$ & $28.37 \%$ & 1.77 & 2.59 & $51.42 \%$ & $18.18 \%$ \\
\hline Holmés & 1.45 & 2.10 & $58.82 \%$ & $35.29 \%$ & 2.83 & 3.18 & $16.30 \%$ & $58.70 \%$ \\
\hline Lalo & 1.28 & 1.81 & $65.22 \%$ & $15.94 \%$ & 1.86 & 3.00 & $57.14 \%$ & $42.86 \%$ \\
\hline Massé & 1.43 & 1.95 & $54.44 \%$ & $32.22 \%$ & 2.00 & 2.93 & $48.28 \%$ & $44.83 \%$ \\
\hline Massenet & 1.23 & 1.86 & $72.66 \%$ & $14.84 \%$ & 2.11 & 2.81 & $38.60 \%$ & $35.09 \%$ \\
\hline Reber & 1.65 & 2.02 & $35.96 \%$ & $58.43 \%$ & 1.98 & 2.65 & $40.91 \%$ & $30.30 \%$ \\
\hline Reyer & 1.11 & 2.00 & $88.89 \%$ & $11.11 \%$ & 3.33 & 3.33 & $0.00 \%$ & $33.33 \%$ \\
\hline \multirow[t]{3}{*}{ Saint-Saëns } & 1.45 & 2.00 & $54.55 \%$ & $45.45 \%$ & 1.72 & 2.78 & $59.65 \%$ & $28.07 \%$ \\
\hline & \multicolumn{4}{|c|}{ compound duple } & \multicolumn{4}{|c|}{ simple quadruple } \\
\hline & $\begin{array}{c}\text { avg. } \\
\text { with } \\
\text { downbeats }\end{array}$ & $\begin{array}{c}\text { avg. } \\
\text { without } \\
\text { downbeats }\end{array}$ & $\begin{array}{c}\% \\
\text { ending } \\
\text { on beat } 1\end{array}$ & $\begin{array}{c}\% \\
\text { ending } \\
\text { on beat } 2\end{array}$ & $\begin{array}{c}\text { avg. } \\
\text { with } \\
\text { downbeats }\end{array}$ & $\begin{array}{c}\text { avg. } \\
\text { without } \\
\text { downbeats }\end{array}$ & $\begin{array}{c}\% \\
\text { ending } \\
\text { on beat } 1\end{array}$ & $\begin{array}{c}\% \\
\text { ending } \\
\text { on beat } 3\end{array}$ \\
\hline $\begin{array}{r}\text { German } \\
\text { overall }\end{array}$ & 1.56 & 1.95 & $43.15 \%$ & $39.51 \%$ & 2.30 & 2.88 & $35.55 \%$ & $33.77 \%$ \\
\hline Beethoven & 1.36 & 1.90 & $60.38 \%$ & $26.42 \%$ & 2.92 & 3.09 & $8.33 \%$ & $83.33 \%$ \\
\hline Brahms & 1.59 & 1.93 & $36.84 \%$ & $41.52 \%$ & 2.27 & 3.13 & $40.18 \%$ & $33.04 \%$ \\
\hline Franz & 1.55 & 2.00 & $44.79 \%$ & $50.52 \%$ & 2.45 & 3.43 & $40.22 \%$ & $25.00 \%$ \\
\hline Hensel & 1.46 & 1.95 & $51.98 \%$ & $32.67 \%$ & 2.05 & 2.84 & $42.75 \%$ & $25.65 \%$ \\
\hline Lang & 1.46 & 1.89 & $48.28 \%$ & $41.38 \%$ & 1.92 & 2.92 & $52.43 \%$ & $25.24 \%$ \\
\hline Loewe & 1.03 & 2.00 & $96.88 \%$ & $3.13 \%$ & 1.15 & 2.25 & $87.88 \%$ & $3.03 \%$ \\
\hline Mahler & 1.79 & 2.00 & $21.43 \%$ & $78.57 \%$ & 2.55 & 3.16 & $28.24 \%$ & $41.18 \%$ \\
\hline Mendelssohn & 1.49 & 2.01 & $51.60 \%$ & $41.10 \%$ & 1.82 & 2.63 & $49.72 \%$ & $19.55 \%$ \\
\hline Schubert & 1.60 & 1.98 & $38.86 \%$ & $47.34 \%$ & 2.18 & 2.92 & $38.80 \%$ & $39.42 \%$ \\
\hline C. Schumann & 1.19 & 1.67 & $71.43 \%$ & $0.00 \%$ & 1.44 & 2.00 & $55.56 \%$ & $0.00 \%$ \\
\hline R. Schumann & 1.54 & 1.85 & $36.36 \%$ & $37.76 \%$ & 2.31 & 2.88 & $30.47 \%$ & $34.56 \%$ \\
\hline Strauss & 1.74 & 2.10 & $33.01 \%$ & $30.10 \%$ & 2.48 & 3.07 & $28.74 \%$ & $25.86 \%$ \\
\hline Wolf & 1.60 & 2.02 & $41.15 \%$ & $27.08 \%$ & 2.68 & 3.15 & $21.71 \%$ & $44.96 \%$ \\
\hline
\end{tabular}

Table 10. Average metrical location of phrase endings, with and without downbeats, and percentage of phrases ending on downbeat or secondarily stressed beat. 
As before, Table 10 illustrates the tremendous amount of variability in individual composer practice within language. For example, in compound duple meters, Reyer ended phrases on the downbeat $88.89 \%$ of the time, while Reber only did so $35.96 \%$ of the time. There is even more variability for the German composers in compound duple meters, where Loewe ended phrases on the downbeat a remarkable $96.88 \%$ of the time, but Mahler only did so $21.43 \%$ of the time.

As with the phrase beginnings, we may be able to determine something about individual compositional style from looking at where composers end phrases. For example, if we look at the percentage of time that Reyer ends on downbeats or secondarily stressed beats in compound duple $(88.89 \%$ and $11.11 \%$, respectively), we can see that in compound duple meters, Reyer only ended phrases on beats 1 or 2, and never on a weak beat. Similarly, in simple quadruple, Lalo ended phrases on the downbeat $57.14 \%$ of the time and on the secondarily stressed beat $42.86 \%$ of the time, meaning that he never ended a phrase on a weak beat in simple quadruple meter.

Comparing that distribution of phrase endings to the way Lalo ended phrases in compound duple meters, we can see that Lalo ended far fewer phrases on the secondarily stressed beat in compound duple meter (15.94\%) than in the simple quadruple, indicating that he did not treat phrase endings similarly across the two metrical categories.

This is similarly illustrated in Beethoven's phrase endings across metrical categories. In compound duple meters Beethoven ended $60.38 \%$ of his phrases on the downbeat, with only $26.42 \%$ of his phrases cadencing on the secondarily stressed beat; in contrast, in simple quadruple he ended phrases on the downbeat only $8.33 \%$ of the time, cadencing on the secondarily stressed beat in $83.33 \%$ of his phrases.

Combining the information from Table 9 and Table 10 together can provide a fascinating glimpse into elements of compositional style that have not yet been studied but may prove useful for music scholars. For example, compared to other German composers, Clara Schumann tended to begin her phrases relatively early in the measure, and tended not to begin her phrases on downbeats or secondarily stressed beats, as evidenced by the low percentages for compound duple meters, and the two $0 \%$ for phrase beginnings on stressed beats in simple quadruple meters. Her phrase endings also happen relatively early in the measure, and never occur on the secondarily stressed beat. If we contrast these statistics with those of Robert Schumann, we can see that Robert tended to start his phrases later in the measure than Clara, and began his phrases on the downbeat more frequently than did Clara. In addition, Robert's phrase endings happen on both the downbeat and the secondarily stressed beat with approximately the same frequency. It is possible that the location of phrase beginnings and phrase endings is a distinguishing characteristic between Robert's compositional style and Clara's, and it might be useful in studying pieces where the authorship is questionable.

\section{CONCLUSION}

Rothstein's article proposes characteristics related to phrase beginnings and phrase endings based on apparent nationalistic conceptions of meter in general, and compound meter in particular. His discussion includes a detailed history of metrical conceptions from the $17^{\text {th }}$ century to the early $19^{\text {th }}$ century, illustrating how theorists conceived of meter and how composers manifested those theories into their music. In addition, Rothstein discusses other potential influences on composer's treatment of meter; most notably for this study, the concept of the accento comune and the influence of poetic meter on phrase length and cadences. These influences require further study.

The focus of this study was to determine to what degree $19^{\text {th }}$ century French and German art song exhibited the phrase beginning and ending characteristics that his study of $18^{\text {th }}$ and early $19^{\text {th }}$ century repertoire illustrated so thoroughly. Thus, results that do not agree with Rothstein's characteristics are not a refutation of Rothstein's national metrical types; rather, such a refutation simply means that in this genre and time period, composers may have had other constraints (such as poetic meter) or, most likely, that the conception of meter continued to change throughout the $19^{\text {th }}$ century. This too is an area requiring further examination.

This study also illustrates that large-N database studies can provide musically relevant results by looking not only at differences across languages, but also by studying data for individual composers. The brief discussion here highlighted particular rhythmic characteristics of certain composers, but there is much more that can be said about the rhythmic characteristics of individual composers, and much work to be done to follow up on this line of inquiry. 


\section{NOTES}

[1] The preceding definitions and quotations all come from Rothstein 2008, pp. 115-117.

[2] It is certainly possible that harmonic motion may have continued under a tied note, resulting in the harmonic cadence happening in a different location than the melodic cadence. As the database did not contain harmonic information, there was not a way to control for this possibility. Given the large number of phrases in the database, it is likely that the phrases in which this happens would not significantly alter the results in any way.

\section{REFERENCES}

Houle, G. (1987). Meter in music, 1600-1800: Performance, perception, and notation. Bloomington: Indiana University Press.

Humdrum Toolkit Ver. 2.2 beta for Mac OS 10.2-10.3. David Huron. Columbus, OH.

Rothstein, W. (2008). National metrical types in music of the eighteenth and early nineteenth centuries. In: D. Mirka \& K. Agawu, (Eds.), Communication in $18^{\text {th }}$-century music. Cambridge, UK: Cambridge University Press, pp. 112159. 